\title{
Is Intrathecal Baclofen Pump Safe as It Thought To Be?
}

\author{
Omar Al Misnid* \\ Department of Anesthesia, Qassim University, Saudi Arabia
}

Submission: June 14, 2018; Published: June 21, 2018

*Corresponding author: Omar Al Misnid, Department of Anesthesia, Qassim University, 52377 2629, Buraydah Saudi Arabia

Tel: 00966561205555; Email: dr.almisnid@hotmail.com

\begin{abstract}
Introduction: Intrathecal baclofen pump is used widely to treat spasticity that caused by variable etiologies either spinal or cerebral in origin. The intrathecal route of administration is more effective and carries fewer incidences of intolerable side effects compare to the oral route, yet side effects still could happen with the intrathecal route, in particular the risk of intrathecal baclofen withdrawal syndrome. Intrathecal baclofen withdrawal syndrome is a potentially life-threatening complication of baclofen pumps caused by an abrupt discontinuation of intrathecal baclofen regardless of the cause of discontinuation.
\end{abstract}

Case presentation: A 31 year old man with a history of spastic paraplegia, secondary to spinal cord injury caused by a road traffic accident years ago, was brought to the emergency room with status epilepticus, low level of consciousness, hypotension, aspiration pneumonia and rhabdomyolysis. The patient had a similar attack before after missing a refilling appointment of his baclofen pump, the diagnosis of intrathecal baclofen withdrawal syndrome was established. The patient was treated with supportive care, norepinephrine, benzodiazepines and refilling of his baclofen pump.

Conclusion: Intrathecal baclofen withdrawal syndrome is a potentially life-threatening complication of baclofen pumps caused by an abrupt discontinuation of intrathecal baclofen regardless of the cause of discontinuation. Most causes of discontinuation that result in intrathecal baclofen withdrawal syndrome were basically human errors which could be prevented by careful and close attention from medical specialists, medical institutions, patients and caregivers. The patients and caregivers should be advised about the importance of keeping scheduled refill visits and educated on proper home care of the baclofen pump and insertion site, pump alarms and the early symptoms of intrathecal baclofen withdrawal and overdose. Finally early recognition of syndrome, the restoration of baclofen administration by the same route and providing the proper supportive care are the main goals in the management of such complication.

Abbreviations: CT: Computed Tomography; ITB: Intrathecal Baclofen; CPK: Creatinine Phosphokinase; GABA: Gamma Amino Butyric Acid; IV: Intravenous; ICU: Intensive Care Unit; ECG: Electro Cardio Graphy

Keywords: Intrathecal; Baclofen; Pump; Withdrawal; Spasticity; GABA; Safety

\section{Introduction}

Intrathecal baclofen pump is used widely to treat spasticity that caused by variable etiologies either spinal or cerebral in origin. The intrathecal route of administration is more effective and carries fewer incidences of intolerable side effects compare to the oral route The intrathecal route is not yet without any risks, the most common reported side effects include drowsiness, lightheadedness, dizziness, nausea and vomiting, hypotension, headache and motor weakness while the most serious and life threatening could be limited to baclofen overdose and withdrawal syndrome.

Intrathecal baclofen withdrawal syndrome is a potentially life- threatening complication of baclofen pumps caused by an abrupt discontinuation of intrathecal baclofen regardless of the cause of discontinuation. The benefits of Intrathecal baclofen is well known, as literature does support the benefits over risks regarding intrathecal baclofen. In this case a question is raised about how safe an intrathecal baclofen pump is? As the patient suffered from this complication twice within four years. The results did show higher benefits than risks in literatures but does the scale change in case of different circumstances like different medical institutions, selectivity procedures of the patients, or the education level of the caregivers.

\section{Case Presentation}

A 31 year old morbidly obese man was brought by his family to the emergency room with recurrent episodes of seizure and low level of consciousness. Initial assessment was immediately done by the emergency staff along with the essential steps in the management of status epilepticus. The patient had a medical history of spastic paraplegia secondary to spinal cord injury resulted from road traffic accident twenty years back. He 
had a baclofen pump inserted twelve years back for his lower limb spasticity. The patient has suprapubic urinary catheter and colostomy bag in place. The patient follows up with a pain specialist for his intrathecal baclofen pump for regular check-up and refill every two months, unfortunately at his last appointment, which was two weeks ago, his doctor was not available according to the family while the patient and his family decided to wait and did not seek medical help from another physician or institution.

According to the patient's family, he had seven attacks of tonicclonic seizure each last one to two minutes without gaining his full consciousness before reaching the hospital. The family mentioned a history of similar attack four years ago which happened after missing an appointment with his pain specialist. In the emergency room, the patient presented with status epilepticus, decrease level of consciousness and fever. The patient received multiple doses of benzodiazepines finally seizures were terminated and airway got secured with oral endotracheal tube. While the patient was being sedated, essential blood works, Cultures, chest X-Ray and CT brain were obtained. Invasive monitoring was done including arterial line and central venous catheter. The patient was initially hemodynamically unstable with heart rate of 118 beats per minute, Blood pressure 85/43 mmHg, Oxygen saturation 98\% with $\mathrm{FiO}_{2}$ 0.50 , and a temperature of $38.7^{\circ} \mathrm{C}$. The patient was resuscitated with Intravenous (IV) fluid bolus of two liters was given and Norepinephrine infusion was started meanwhile intensive care, neurology and chronic pain service were consulted for further management. On examination, the patient was intubated and sedated with fentanyl and midazolam infusions.

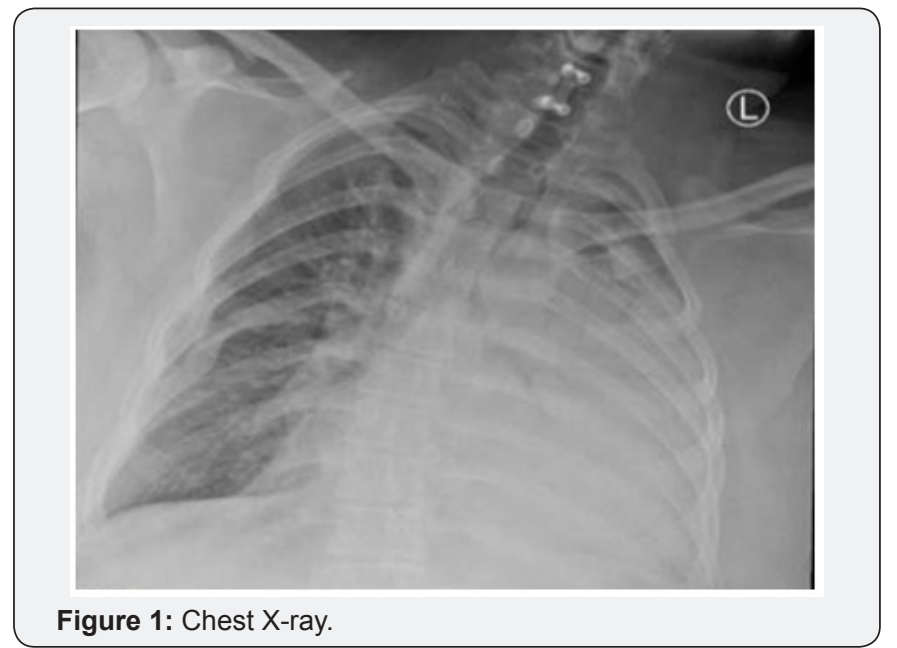

Neurologically, the patient's pupil measured $2 \mathrm{~mm}$ and reactive with Glasgow coma scale of 4 and lower limb spasticity. On chest examination, patient had decrease air entry in the left lung with unremarkable cardiac auscultation and stable hemodynamics parameters with norepinephrine infusion 0.1 microgram per kilogram per minute. Urine output was within normal through the suprapubic catheter and the abdomen was soft and lax with palpable baclofen pump and colostomy bag in place. The initial investigation results were as follow; 12 leads ECG showed Sinus tachycardia with prolonged QTc and non-specific ST segment and $\mathrm{T}$ wave changes. There was diffuse air space opacity at upper and mainly lower lobes of the left lung on chest X-ray (Figure 1). Arterial blood gas was $\mathrm{PH} 7.34, \mathrm{PaO}_{2} 118 \mathrm{mmHg}, \mathrm{PaCO}_{2} 30 \mathrm{mmHg}$, bicarbonate $16.7 \mathrm{mmol} / \mathrm{L}$, Base Excess (BE) $-8.0 \mathrm{mmol} / \mathrm{L}$ and Lactic acid $1.9 \mathrm{mmol} / \mathrm{L}$. Complete blood count showed white blood cells $19.1610^{\wedge}$ 9/L, Hemoglobin $133 \mathrm{~g} / \mathrm{L}$ and Platelets count 155 $10^{\wedge} 9 / \mathrm{L}$. Renal profile and electrolytes showed serum creatinine $66 \mu \mathrm{mol} / \mathrm{L}$, potassium $3.5 \mathrm{mmol} / \mathrm{L}$, sodium $141 \mathrm{mmol} / \mathrm{L}$, Chloride $110 \mathrm{mmol} / \mathrm{L}$, calcium 1.73, and bicarbonate $16 \mathrm{mmol} / \mathrm{L}$.

While liver function tests showed Aspartate Amino Transferase (ALT) $70 \mathrm{U} / \mathrm{L}$, Alanine Amino Transferase (AST) $254.3 \mathrm{U} / \mathrm{L}$, alkaline phosphatase $67 \mathrm{U} / \mathrm{L}$, Gamma-Glutamyl Transferase (GGT) $14 \mathrm{IU} / \mathrm{L}$, total bilirubin $15 \mathrm{umol} / \mathrm{L}$, Albumin $31 \mathrm{~g} / \mathrm{L}$ and Glucose Random $7.40 \mathrm{mmol} / \mathrm{L}$. Coagulation profile showed prothrombin time 16.9 seconds, partial thromboplastin time 34.8 seconds, and INR 1.4. The result of serum Creatinine Phosphokinase (CPK) was $12.654 \mathrm{U} / \mathrm{L}$ and Troponin T $1.900 \mathrm{ug} / \mathrm{L}$. Brain CT showed no evidence of acute intracranial abnormality. Echocardiograph was within normal except for mild increase in right ventricular systolic pressure. In addition to midazolam, fentanyl and norepinephrine, the patient was started on meropenem, tamiflu, vancomycin, phenytoin, omeprazole and subcutaneous Heparin.

The broad spectrum of antibiotics was initiated to cover the other differential diagnosis Septic shock, meningitis and pneumonia. The patient was then transferred to intensive care unit (ICU) for further management and care. The intrathecal baclofen pump was checked and filled next day by the pain specialist. The patient was also treated with vigorous IV fluid administration in addition to sodium bicarbonate infusion which was aggressive in the first few days in response to episodes of decreased urine output. On the fourth ICU day, the patient showed significant clinical improvement; Glasgow coma scale of 14 to 15 , maintaining oxygen saturation with Low ventilator settings and $\mathrm{FiO}_{2}$ of 0.30 and norepinephrine was discontinued with stable hemodynamics.

The patient was successfully weaned off the ventilator next day which was tolerated very well and kept on Continuous Positive Airway Pressure (CPAP) of 8 to $12 \mathrm{~cm} \mathrm{H}_{2} \mathrm{O}$. Laboratory tests were improving too, serum $\mathrm{CPK}$ was coming gradually down to $8,326 \mathrm{U} / \mathrm{L}$. On the ninth ICU day, the patient was transferred to the medical ward, clinically the Patient was breathing on room air with Oxygen saturation $98 \%$ and his latest serum CPK was 1,287 $\mathrm{U} / \mathrm{L}$. Two days later the serum CPK came down to $716 \mathrm{U} / \mathrm{L}$ and the patient was discharged home next day.

\section{Discussion}

Baclofen is a chemical derivative of the Inhibitory neurotransmitter Gamma-Amino butyric Acid (GABA). The precise mechanisms of action of baclofen as a muscle relaxant and anti-spastic agent are not fully understood [1]. Baclofen mostly exhibit its action through a selective binding and activation of GABA-B receptors in the central nervous system mainly in the spinal cord which leads to decrease in neurotransmitter release. 
Baclofen has both presynaptic and postsynaptic inhibitory properties predominantly preventing presynaptic calcium influx which results in decreased muscle tone and muscle spasm. Baclofen has been used in oral formulation since the $1960 \mathrm{~s}$ and improves spasms in $70 \%$ to $96 \%$ of patients [2]. When compared to the oral route, intrathecal dosing ensures higher cerebrospinal fluid concentrations that are difficult to maintain with oral administration of the drug since only small fraction of the drug actually reaches the main site of action in the spinal cord when using the oral route [3]. Facing this fact high dose of oral baclofen usually needed to overcome the poor response and have a significant clinical outcome and improvement in relieving the symptoms in cost of having more likelihood of systemic side effects of the drug.

The Intrathecal Baclofen (ITB) has been used and found to be more efficacious than the oral route since the 1980s in patients with spasticity unresponsive to maximal doses of oral baclofen or other oral anti-spastic medications [3]. The precise direct delivery of baclofen dose into the spinal subarachnoid space by the intrathecal route results in a significant control of the symptoms at thousand times lower than the doses needed for oral baclofen and with plasma concentrations hundred times lower than those following oral administration and so less systemic side effects of the drug $[1,4]$. The intrathecal route is not yet without any risks, the most common reported side effects include drowsiness, lightheadedness, dizziness, nausea and vomiting, hypotension, headache and motor weakness while the most serious and life threatening could be limited to baclofen overdose and withdrawal syndrome.

The ITB withdrawal syndrome likely result from chronic administration of the drug leading to down regulation of GABA-B receptors and loss of the chronic inhibitory effect specially on postsynaptic receptors which eventually will result in unopposed excitatory effects in case of abrupt discontinuation of ITB. Withdrawal symptoms typically occurs in the first few hours to 48 hours after abrupt discontinuation of the drug, regardless of the cause, with initial symptoms like lightheadedness, dizziness, anxiety, and most important worsening or return of spasticity and this mild symptoms could progress rapidly to hyperthermia, altered mental status, seizures, muscle rigidity, rhabdomyolysis, acute kidney injury, disseminated intravascular coagulation, multisystem organ failure, cardiac arrest, coma and death $[4,5]$.

In April 2002 following case reports of ITB withdrawal syndromes, FDA announced a drug label warning for baclofen withdrawal syndrome and further more information regarding the prevention of such life threatening complication by careful screening procedure, adequately equipped medical institutions, programming, monitoring of the infusion system, refill scheduling and procedures, pump alarms and advise Patients and caregivers about the importance of keeping scheduled refill visits and educate them about the early symptoms of baclofen withdrawal [6]. Most common causes of abrupt discontinuation of ITB which result in withdrawal were basically human errors which could be prevented and so such careful education and strict procedures are necessary to keep the benefits outrange the risks when it comes to ITB.

Management of ITB withdrawal syndrome starts with an early recognition of the syndrome as any delay in diagnosing such complication will eventually lead to rapid worsening and higher morbidity and mortality. The definitive treatment once the diagnosis been stablished is the restoration of drug administration by the same route at or near the same dosage as before therapy was interrupted in addition to providing supportive care that needed according to the clinical status of the patient $[4,7]$. It is not uncommon for the restoration of intrathecal baclofen being delayed due to many reasons, in such cases high doses of benzodiazepine might be the first proper line of alternative measurement that is suggested by many literatures in controlling spasticity and seizures $[4,7]$. Benzodiazepine activation of GABA-A receptor relieves spasticity and rigidity by different presynaptic and postsynaptic mechanisms than baclofen and for that reason benzodiazepine is not affected by the down regulation of GABA-B receptors induced by intrathecal baclofen [7]. Oral baclofen is one of the logical alternatives in the management of ITB withdrawal syndrome, but the failure with oral baclofen has been reported since the level achieved in the spinal subarachnoid space is low by oral route as discussed earlier and the down regulation of GABA-B receptors induced by intrathecal baclofen $[3,4]$.

Other medications have been used in the management of ITB withdrawal syndrome like dantrolene, cyproheptadine, propofol, dexmedetomidine and tizanidine. Dantrolene inhibits excitation-contraction coupling in skeletal muscle by blocking the ryanodine receptor 1 which result in less release of calcium from the sarcoplasmic reticulum. Dantrolene showed to be helpful in relieving the spasticity and possibly fever to some extend but did not show any other significant control of the other symptoms like seizure and hemodynamic instability [4,7]. Regardless how malignant hyperthermia or neuroleptic malignant syndrome could show similar clinical presentation as ITB withdrawal syndrome, it is now clear the pathophysiology is quite different. Dexmedetomidine is a selective alpha-2 adrenergic receptor agonist with sedative and analgesic properties.

A recent case report of using dexmedetomidine successfully in a patient with severe ITB withdrawal syndrome have been reported, The withdrawal symptoms was not controlled with high doses of enteral baclofen and benzodiazepine [8]. Another case was published using dexmedetomidine to control the withdrawal symptoms in a patient who was on oral baclofen [9]. Although the neuropharmacologic actions of propofol and baclofen are not fully understood, several cases were managed successfully with titrated doses of propofol to control the withdrawal symptoms [10]. Last but not least is the prevention of acute kidney Injury in presence of rhabdomyolysis, the management of spasticity as discussed earlier could be counted as the first line of preventing kidney 
injury in addition to early and vigorous IV fluid administration and maintaining urine output. Other interventions like sodium bicarbonate, mannitol and to less extend loop diuretics could be considered in case the urine output could not be maintained despite the controversy and the lack of evidence.

\section{Conclusion}

Intrathecal baclofen withdrawal syndrome is a potentially lifethreatening complication of baclofen pump caused by an abrupt discontinuation of intrathecal baclofen regardless of the cause of discontinuation. Most causes of discontinuation that result in intrathecal baclofen withdrawal syndrome were basically human errors which could be prevented by careful and close attention from medical specialists, medical institutions, patients and caregivers. The patients and caregivers should be advised about the importance of keeping scheduled refill visits and educated on proper home care of the baclofen pump and insertion site, pump alarms and the early symptoms of intrathecal baclofen withdrawal and overdose. Reduction and discontinuation of baclofen should be done slowly and with careful monitoring by the specialists. The keys to manage such complication are an early recognition of syndrome, the restoration of baclofen administration by the same route and providing the proper supportive care are the main goals in the management of such complication. Finally, benzodiazepine, dexmedetomidine and propofol could be considered great alternatives to control the withdrawal symptoms if restablishing the ITB is going to take time.

\section{Acknowledgements}

A written consent was taken from the patient for the publication of this case.

\section{Conflict of interest}

There is no conflict of interest exists to declare.

\section{References}

1. Allerton CA, Boden PR, Hill RG (1989) Actions of the GABAB agonist, $(-)$-baclofen, on neurones in deep dorsal horn of the rat spinal cord in vitro. Br J Pharmacol 96(1): 29-38.

2. Dario A, Tomei G (2004) A benefit-risk assessment of baclofen in severe spinal spasticity. Drug Saf 27(11): 799-818.

3. Greenberg MI, Hendrickson RG (2003) Baclofen withdrawal following removal of an intrathecal baclofen pump despite oral baclofen replacement. J Toxicol Clin Toxicol 41(1): 83-85.

4. Mohammed I, Hussain A (2004) Intrathecal baclofen withdrawal syndrome- a life-threatening complication of baclofen pump: a case report. BMC Clin Pharmacol 4: 6.

5. Sampathkumar P, Scanlon PD, Plevak DJ (1998) Baclofen withdrawal presenting as multiorgan system failure. Anesth Analg 87: 562-563.

6. (2002-2016) Intrathecal baclofen injections, U.S. food and drug administration.

7. Coffey RJ, Edgar TS, Francisco GE, Graziani V, Meythaler JM, et al. (2002) Abrupt withdrawal from intrathecal baclofen: recognition and management of a potentially life-threatening syndrome. Arch Phys Med Rehabil 83(6): 735-741.

8. Morr S, Heard CM, Li V, Reynolds RM (2015) Dexmedetomidine for Acute Baclofen Withdrawal. Neurocrit Care 22(2): 288-292.

9. Gawron Aubrey, Picano John, Perrello Anna, Brewer Thomas, Ahmed Saman (2018) Enteral baclofen withdrawal managed acutely with dexmedetomidine. Critical Care Medicine 46(1): 452.

10. Gareth L Ackland, Rick Fox (2005) Low-dose Propofol Infusion for Controlling Acute Hyperspasticity after Withdrawal of Intrathecal Baclofen Therapy Anesthesiology 103(3): 663-665.

\section{Your next submission with Juniper Publishers} will reach you the below assets

- Quality Editorial service

- Swift Peer Review

- Reprints availability

- E-prints Service

- Manuscript Podcast for convenient understanding

- Global attainment for your research

- Manuscript accessibility in different formats

( Pdf, E-pub, Full Text, Audio)

- Unceasing customer service

Track the below URL for one-step submission https://juniperpublishers.com/online-submission.php 